\title{
Impact of growing conditions on the competitive ability of Camelina sativa (L.) Crantz (Camelina)
}

\author{
Phillip B. Davis, Bruce Maxwell, and Fabian D. Menalled \\ Montana State University - Land Resources and Environmental Sciences, Bozeman, Montana, United States. \\ Received 21 August 2012, accepted 2 November 2012.
}

\begin{abstract}
Davis, P. B., Maxwell, B. and Menalled, F. D. 2013. Impact of growing conditions on the competitive ability of Camelina sativa (L.) Crantz (Camelina). Can. J. Plant Sci. 93: 243-247. It has been claimed that Camelina sativa, a recently introduced crop in the northern Great Plains, is a highly competitive species. However, this issue has not been formally tested. Utilizing replacement series diagrams, we assessed the importance of growing conditions in the competitive ability of C. sativa. Results indicated that canola and Bromus tectorum were superior competitors in both loam and sandy soils, thus providing evidence that $C$. sativa may not be as competitive as previously indicated.
\end{abstract}

Key words: Crop-weed competition, replacement series, biofuels, Bromus tectorum, canola

Davis, P. B., Maxwell, B. et Menalled, F. D. 2013. Impact des conditions de croissance sur la compétitivité de Camelina sativa (1.) crantz (caméline). Can. J. Plant Sci. 93: 243-247. On soutient que Camelina sativa, une culture d'introduction récente dans le nord des Grandes plaines, est une espèce très concurrentielle. Cependant, la chose n'a jamais été formellement vérifiée. Recourant à des diagrammes de séquences de remplacement, les auteurs ont évalué l'importance des conditions de croissance pour la compétitivité de $C$. sativa. Les résultats indiquent que le et Bromus tectorum sont de meilleurs concurrents sur les loams et les sols sablonneux, preuve que $C$. sativa pourrait ne pas être aussi compétitive qu'on le croit.

Mots clés: Concurrence culture-adventice, séquences de remplacement, biocarburants, Bromus tectorum, canola

Camelina sativa (L.) Crantz (gold of pleasure, large seeded false flax), a proposed biofuel species, is an oilseed crop and a member of the Brassicaceae family. It has been recently introduced to the United States of America and Canada with most production taking place in Montana and North Dakota (Schillinger et al. 2012). Camelina sativa has the potential to become widely cultivated as it is aptly suited for the adverse environmental conditions that dominate the region. First, C. sativa is tolerant to frost and can therefore be planted as early as mid-March (Putnam et al. 1993). Second, it is capable of withstanding drought and can tolerate low-quality, nutrient-poor soils (Gilbertson et al. 2007). Third, C. sativa is a short-season crop with the ability to escape late summer heat (Angadi et al. 2000). Finally, there is increased interest in $C$. sativa as a potential biofuel crop, and a source of omega-3 fatty acids and natural antioxidants (Pilgeram et al. 2007).

Although it has been claimed that $C$. sativa is highly competitive against weeds (Pilgeram et al. 2007), to our knowledge, this issue has not been formally assessed. Assessing the competitive ability of $C$. sativa is the first step in the design of a sustainable weed management program that takes advantage of the suppressive effect of crops to minimize herbicide inputs. This study evaluated the relative importance of growing conditions in the competitive ability of $C$. sativa. Specifically, we assessed how soil characteristics and the presence of Bromus tectorum (L.) (downy brome, cheatgrass) modify the competitive interactions between $C$. sativa and spring canola (Brassica napus L.).

In this study, we used canola as a model broadleaf weed species for which much research has been conducted on its competitive ability (summarized in Zimdahl 2004). Bromus tectorum is one of the most problematic invasive species throughout North America, particularly in the western USA. Since its introduction to North America in the late 1800s, B. tectorum has spread into every state in the Intermountain West. Bromus tectorum negatively impacts crop and non-crop habitats through resource competition, by reducing productivity, modifying biological diversity, and altering wildfire frequency and intensity (Chambers et al. 2007).

\section{MATERIALS AND METHODS}

The relative competitiveness of $C$. sativa var. Celine against glyphosate-resistant spring canola (var. Roundup Ready $45 \mathrm{H} 21$ ) and B. tectorum was assessed in a full factorial experiment under greenhouse conditions in

Abbreviations: RY, relative yield; RYT, relative yield total 
Bozeman, MT. Three trials of the same experiment were conducted in two greenhouses with a 16-h day: night photoperiod. Trials 1 and 3 were conducted in the same greenhouse and had average day and night temperatures of 26 and $19^{\circ} \mathrm{C}$, respectively. Trial 2 was conducted in a second greenhouse with average day and night temperatures of 22.5 and $20.5^{\circ} \mathrm{C}$, respectively. Two explanatory variables (soil type and presence of $B$. tectorum), each with two levels, were included in this study. Each soil type contained a mixture of washed concrete sand, loam soil, and Canadian Sphagnum peat moss. The first mixture, "MSU", was used in the ratio of 1:1:1 and had AquaGro $2000 \mathrm{G}$ (Aquatrols, Paulsboro, $\mathrm{NJ}$ ) wetting agent blended in at $0.59 \mathrm{~kg} \mathrm{~m}^{-3}$ (MS, hereafter). The second soil treatment, "sandy", was the same as the MSU except with $2 \times$ sand (SS, hereafter). Soils were steam pasteurized at $80^{\circ} \mathrm{C}$ for $45 \mathrm{~min}$. Locally collected seeds of $B$. tectorum were included in the experiment as either present at the density of 12 plants $\operatorname{pot}^{-1}(\mathrm{WB}$, hereafter), or absent $(0 \mathrm{~B}$, hereafter).

Camelina sativa and canola were grown at a constant density of 12 plants in a replacement series design at five ratios $(0: 1,25: 75,50: 50,75: 25,1: 0)$, in $14 \times 18 \mathrm{~cm}$ (ht $\times$ diam) pots. After pots were filled with soil, $24 B$. tectorum seeds were randomly scattered on the soil surface. Next, $C$. sativa and canola were sown using cardboard templates with three seeds of either canola or C. sativa placed in each hole and covered with approximately $1 \mathrm{~cm}$ of soil. Each treatment combination was replicated six times (120 pots per trial) in a completely randomized design. All pots were hand watered regularly to field capacity and rotated weekly.

Camelina sativa, canola, and B. tectorum plants were thinned at 1 wk after planting to obtain desired densities. Where germination did not occur, seedlings were transplanted to maintain the targeted density. All plants were harvested $7 \mathrm{wk}$ after planting. Phenologically, this was near the end of the flowering stage for $C$. sativa and canola, while B. tectorum was still in its vegetative phase. All above-ground parts were cut at the soil surface, separated by species, placed in paper bags, dried, and weighed on a per pot basis.

\section{Data Analysis}

Following Radosevich et al. (2007), C. sativa and canola relative yield (RY) and relative yield total (RYT) were calculated for all treatment combinations at each planting ratio as:

$$
\begin{aligned}
& \mathrm{RY}_{\mathrm{A}}=\mathrm{Y}_{\mathrm{AB}} / \mathrm{Y}_{\mathrm{A}} \\
& \text { and } \\
& \mathrm{RYT}=\mathrm{RY}_{\mathrm{A}}+\mathrm{RY}_{\mathrm{B}}
\end{aligned}
$$

where $R Y_{A}$ is the relative yield of species $A, Y_{A B}$ is the yield of species $A$ in mixture with species $B$, and $Y_{A}$ is the yield of species A in monoculture. RYT is the sum of the relative yields for species $\mathrm{A}$ and $\mathrm{B}$.
Evidence for competitive interactions was investigated with regression analysis to determine if RY data were described more accurately with a quadratic trendline than with a linear trendline (Rejmanek et al. 1989). Briefly, if the RY curve for one species is convex and the RY curve for the other species is concave, it suggests a competitive interaction. Alternatively, if both species' RY curves are convex or if RY and RYT both are concave, the type of interference is that of mutual stimulation or mutual antagonism, respectively. If the RY trends display linear relationships, it is assumed equal competition or no competition, but differentiation between the two is not possible.

Using ANOVA, competing linear models were subjected to a partial $F$-test to determine if the inclusion of quadratic term provided a significantly improved fit over the linear model $(P=0.05)$. Additionally, $C$. sativa and canola RY and RYT were plotted in replacement series diagrams to qualitatively determine the competitive outcomes.

RYT was assessed to determine if any of the combined relative yields for $C$. sativa and canola were significantly different from 1 , as this indicates over-yielding $(\mathrm{RYT}>1)$, mutual antagonism $(\mathrm{RYT}<1)$, or competition for the same resources $(\mathrm{RYT}=1)$ (Williams and McCarthy 2001). To do so, we calculated $95 \%$ confidence intervals of RYT values at each planting ratio (except for monoculture) and treatment combination.

The impact of growing conditions on C. sativa and canola yield was tested by comparing dry biomass of each species when planted alone or with B. tectorum. An appropriate ANOVA model with trial and treatment as fixed variables was used. Because of a significant trial $\times$ treatment interaction $(P<0.001)$, trails were analyzed separately. Within each trial, differences between treatments were further analyzed with multiple comparison tests adjusted using the Holm method (Holm 1979). All analyses were done using $\mathrm{R}$ statistical software (R Development Core Team 2008).

\section{RESULTS}

For all trials and treatments of $C$. sativa, the quadratic model improved fit compared with a straight line $(P<$ 0.01 ). For canola, there were three exceptions where a quadratic model did not more accurately describe the data than a straight line. First, in the 0B-SS treatment in trial 1, the quadratic trend was marginally not different from the linear model $(P=0.053)$. Second, in the WB-SS treatment of trials two and three, the linear trend more accurately described the data $(P=0.06$ and $P=0.15$, respectively). The fact that $\mathrm{RY}$ curves of $C$. sativa were all significantly concave and the majority of canola RY curves were convex indicates that these two species competitively interact for resources (Harper 1977). Specifically, C. sativa was shown to be the inferior competitor (Fig. 1).

In general, RYT values were not different than 1, based on $95 \%$ confidence intervals, indicating that there 
Trial 1
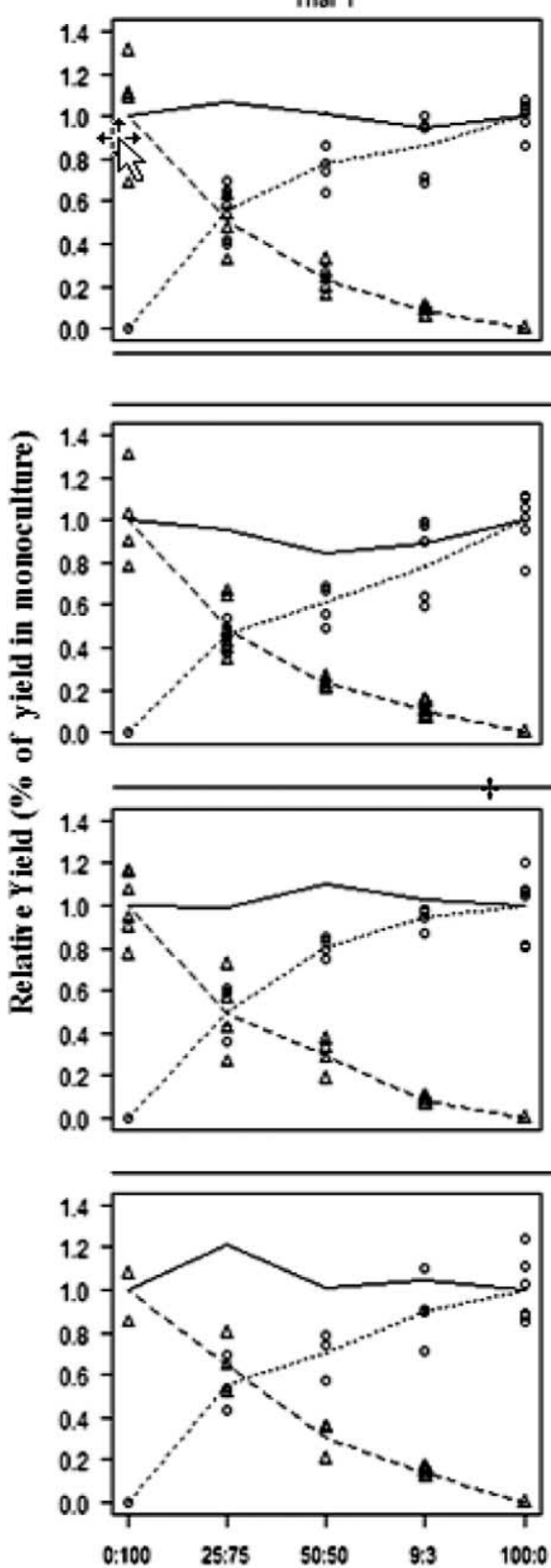

Trial 2
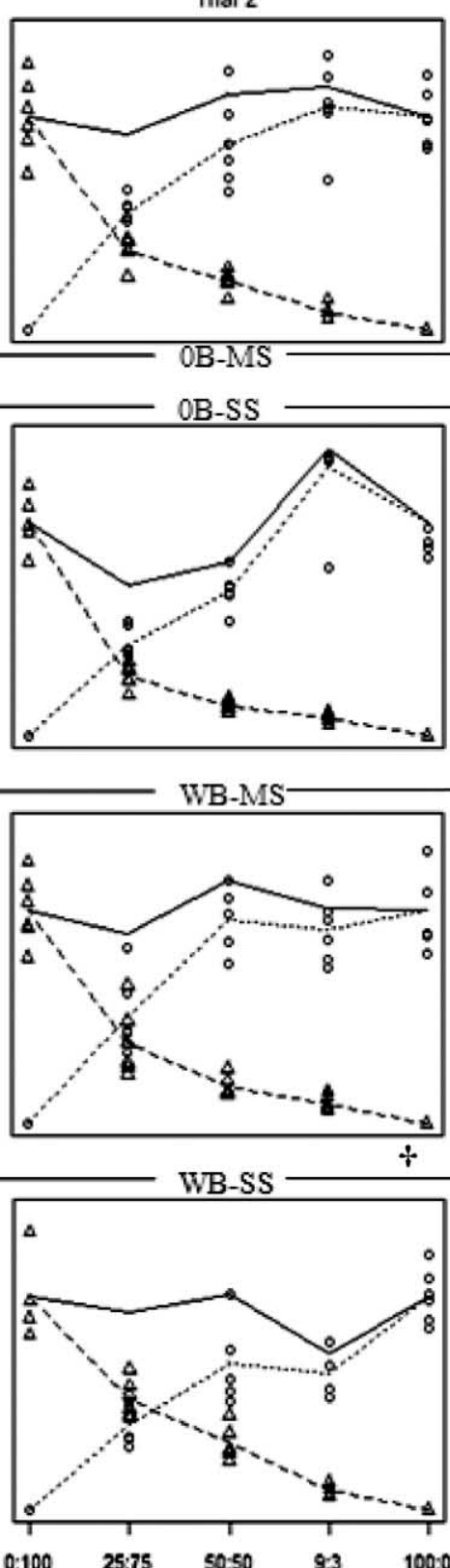

Species proportion (C:CS)
Trial 3
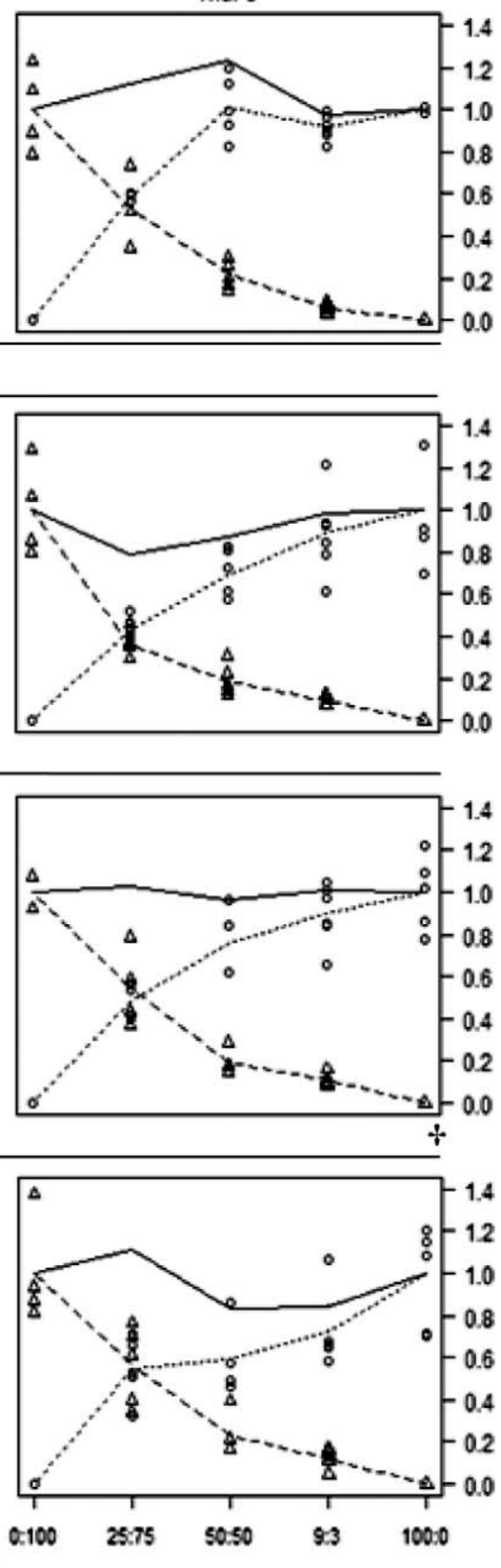

Fig. 1. Replacement series diagrams of each trial $\times$ treatment combination depicting the impact of soil type and presence of Bromus tectorum on the competitive interactions between canola $(\mathrm{C})(\bigcirc)$ and Camelina sativa $(\mathrm{CS})(\triangle)$. Each column of plots represents a trial and the rows represent a treatment [see text for treatment abbreviations and explanation of Relative Yield (RY) and Relative Yield Total (RYT). Trendlines are based on average values and are represented as: $(--),. \mathrm{RY}$ canola; (...), RY C. sativa; (-), RYT. All $C$. sativa RY trendlines deviated significantly from the non-interaction line (i.e., slope $=1$ ) at $P=0.05$. All canola RY trendlines but three deviated significantly from the non-interaction line - those that are not different from a non-interaction line are denoted with $\dagger$ in the upper right-hand corner of the plot.

was no evidence of over- or under-yielding by $C$. sativa and canola when grown together. The only situation where over-yielding occurred was in the 0B-MS treatment at the 50:50 planting proportion, where the average RYT across trials was $1.12 \pm 0.11$ (mean $\pm \mathrm{SD}$ ). Evidence for under-yielding (mutual antagonism) was noticed in 0B-SS treatment at the planting proportions of 25:75 (canola:C. sativa) and 50:50, where RYT values averaged across trials were $0.82 \pm 0.12$ and $0.84 \pm 0.03$, respectively. 
The comparison of canola and C. sativa dry biomass when planted alone or in presence of $B$. tectorum indicated a significant trial $\times$ treatment interaction for both species $(P<0.01)$. For $C$. sativa, the impact of soil type and presence of $B$. tectorum on yield was significant in all trials $(P<0.01)$ (Table 1$)$. Specifically, when grown in the MSU mix, aboveground dry biomass of $C$. sativa was reduced in the presence of $B$. tectorum in trials one and two $(P=0.03$ and $P=0.04$, respectively $)$, but no difference was noticed in the third $(P=0.64)$. When grown in the sandy soil, $C$. sativa yields were lower when B. tectorum was included in two of the three trials $(P<0.001)$. When comparing $C$. sativa yield in the absence of $B$. tectorum, no consistent patterns were observed. In trial 1 , yield was higher in the MSU mix than in the sandy mix $(P=0.02)$, in trial 2 the opposite result occurred $(P=0.04)$, and in trial 3 there was no difference in yield $(P=0.13)$.

Analysis of above-ground dry canola biomass relative to soil type and the presence/absence of $B$. tectorum indicated no treatment differences in trials two and three $(P=0.97$ and $P=0.40$, respectively), but differences were seen in trial $1 \quad(P<0.001$; Table 2$)$ where the highest yield was found in the 0B-MS treatment combination and the lowest yield was in the WB-SS treatment. Similar to $C$. sativa, the presence of $B$. tectorum decreased canola yields in trial 1 . When grown in the MSU soil mix and the sandy soil, canola aboveground dry biomass decreased due to the presence of B. tectorum $(P<0.01$ and $P=0.02$, respectively).

\section{DISCUSSION}

While research has been conducted on the agronomic and economic potential of $C$. sativa, to date, little information exists on its competitive ability. This study suggests that under the temperature range utilized in this study, the relative competitive ability of C. sativa is low and that this competitive balance does not change relative to sand content of soil or with the presence of B. tectorum. Our results indicate that $C$. sativa may not be as competitive as previously indicated (Pilgeram et al. 2007). Accordingly, Pavlista et al. (2012) observed lower

\begin{tabular}{|c|c|c|c|c|}
\hline \multirow[b]{2}{*}{ Trial } & \multicolumn{4}{|c|}{ Treatment } \\
\hline & 0B-MS & 0B-SS & WB-MS & WB-SS \\
\hline 1 & $6.49(1.61) a$ & $4.05(0.92) b$ & $4.50(0.70) b$ & $2.32(0.30) c$ \\
\hline 2 & $5.45(1.00) a$ & $6.87(0.92) b$ & $4.13(0.66) c$ & $3.81(0.81) c$ \\
\hline 3 & $4.67(0.92) a$ & $3.38(0.75) a c$ & $4.05(0.43) a c$ & $2.26(0.58) c$ \\
\hline
\end{tabular}

All trials were analyzed separately because of significant trial $\times$ treatment interaction $(P<0.001)$. Treatments within the same trial (same row) with the same letters are not significantly different based on multiple comparison tests $(P=0.05) ; P$ values adjusted using the Holm method. See text for treatment abbreviations.

\begin{tabular}{|c|c|c|c|c|}
\hline \multirow[b]{2}{*}{ Trial } & \multicolumn{4}{|c|}{ Treatment } \\
\hline & 0B-MS & 0B-SS & WB-MS & WB-SS \\
\hline 1 & $11.18(0.82) a$ & $7.59(0.99) b$ & $8.70(1.38) b c$ & $5.82(0.90) d$ \\
\hline $2^{*}$ & $7.25(0.96)$ & $5.77(1.42)$ & $5.23(0.93)$ & $7.40(0.95)$ \\
\hline $3^{*}$ & $6.37(0.10)$ & $5.56(1.39)$ & $7.61(1.23)$ & $4.93(1.13)$ \\
\hline
\end{tabular}

All trials were analyzed separately because of significant trial $\times$ treatment interaction $(P<0.01)$. Treatments within trial one with the same letters are not significantly different based on multiple comparison tests $(P=0.05) ; P$ values adjusted using the Holm method. *Multiple comparisons not conducted because one-way ANOVA indicated no significant treatment differences for trials two and three $(P=0.97$ and $P=0.40$, respectively). See text for treatment abbreviations.

stem length, root growth, and biomass accumulation in C. sativa than in canola.

Our results suggest that $C$. sativa and canola were competing for the same resources, as is illustrated by the fact that RYT values were rarely different from 1 (Radosevich et al. 2007). It is possible that the outcomes witnessed in this experiment were because canola seeds are larger than $C$. sativa seeds. This difference was further realized upon emergence, as canola seedlings were larger and appeared more vigorous than $C$. sativa seedlings (P. Davis, personal observation). This initial seedling size discrepancy could have influenced the results. As demonstrated by Weiner and Thomas (1986), plant competition is asymmetric and plant growth increases geometrically, particularly early in the life cycle. In accordance, Schillinger et al. (2012) determined that planting date could impact $C$. sativa yield.

This experiment was not performed under field conditions, and previous studies have documented significant differences in functional trait values of plant species when conducted in controlled environments (Shipley and Almeida-Cortez 2003). However, when assessing the applicability of functional traits measured on pot grown plants as representative of those occurring in natural communities, Mokany and Ash (2008) determined that the relative ranking of species was often highly correlated across growing conditions. To confirm our results, it would be necessary to complement our results with those obtained in field conditions. Other factors that should be assessed include the relative time of emergence on competition, differences in competitiveness among weed species, and the relative effect of environmental conditions on weed competitiveness. Furthermore, future studies should be done under temperature regimes representative of the different environments where $C$. sativa could be grown. Despite these knowledge gaps, our findings provide initial information required to design sustainable approaches to grow $C$. sativa. 
Angadi, S. V., Cutforth, H. W., Miller, P. R., McConkey, B. G., Entz, M. H., Brandt, S. A. and Volkmar, K. M. 2000. Response of three Brassica species to high temperature stress during reproductive growth. Can. J. Plant Sci. 80: 396-701.

Chambers, J. C., Roundy, B. A., Blank, R. R., Meyer, S. E. and Whittaker, A. 2007. What makes Great Basin sagebrush ecosystems invasible by Bromus tectorum? Ecol. Monogr. 77: $117-145$.

Gilbertson, P. K., Johnson, B. L., Berti, M. T. and Halvorson, M. A. 2007. Seeding date and performance of specialty oilseeds in North Dakota. Pages 105-110 in J. Janick and A. Whipkey, eds. Issues in new crops and new uses. ASHS Press, Alexandria, VA.

Harper, J. L. 1977. Population biology of plants. Academic Press, London, UK.

Holm, S. 1979. A simple sequentially rejective multiple test procedure. Scand. J. Stat. 6: 65-70.

Mokany, K. and Ash, J. 2008. Are traits measured on pot grown plants representative of those in natural communities? J. Veg. Sci. 19: 119-126.

Pavlista, A. D., Baltensperger, D. D., Isbell, T. A. and Hergert, G. W. 2012. Comparative growth of spring-planted canola, brown mustard and camelina. Ind. Crops Prod. 36: 9-13.

Pilgeram, A. L., Sands, D. C., Boss, D., Dale, N., Wichman, D., Lamb, P., Lu, C., Barrows, R., Kirkpatrick, M., Thompson, B. and Johnson, D. L. 2007. Camelina sativa, a Montana omega-3 and fuel crop. Pages 129-131 in J. Janick and A. Whipkey, eds. Issues in new crops and new uses. ASHS Press, Alexandria, VA.
Putnam, D. H., Budin, J. T., Field, L. A. and Breene, W. M. 1993. Camelina: a promising low input oilseed. Pages 314-322 in J. Janick and J. E. Simon, eds. New crops. Wiley, New York, NY.

R Development Core Team. 2008. R: A language and environment for statistical computing. R Foundation for Statistical Computing. Vienna, Austria.

Radosevich, S. R., Holt, J. S. and Ghersa, C. M. 2007. Ecology of weeds and invasive plants. John Wiley \& Sons, Inc., Hoboken, NJ.

Rejmanek, M., Robinson, G. R. and Rejmankova, E. 1989. Weed-crop competition: experimental designs and models for data analysis. Weed Sci. 37: 276-284.

Schillinger, W. F., Wysocki, D. J., Chastain, T. G., Guy, S. O. and Karow, R. S. 2012. Camelina: Planting date and method effects on stand establishment and seed yield. Field Crops Res. 130: $138-144$.

Shipley, B. and Almeida-Cortez, J. 2003. Interspecific consistency and intraspecific variability of specific leaf area with respect to irradiance and nutrient availability. Ecoscience 10: 74-79.

Weiner, J. and Thomas, S. C. 1986. Size variability and competition in plant monocultures. Oikos 47: 211-222.

Williams, A. C. and McCarthy, B. C. 2001. A new index of interspecific competition for replacement and additive designs. Ecol. Research 16: 29-40.

Zimdahl, R. L. 2004. Weed-crop competition. 2nd ed. Blackwell Publishing, Ames, IA. 